
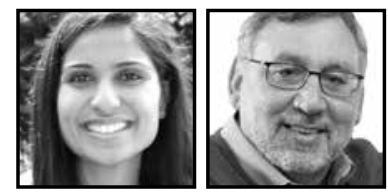

\title{
Uprooting and Settling In: The Invisible Strength of Deficit Thinking
}

\author{
Manu Sharma, University of Windsor \\ John P. Portelli, University of Toronto
}

\begin{abstract}
In our neoliberal context, the field of teacher education faces many challenges and tensions. One crucial challenge that arises deals with the tensions of deficit thinking. Regrettably, these tensions are often left unaddressed due to the demanding subjectbased curriculum learning approach in most Bachelor of Education programs. This paper ${ }^{1}$ examines why deficit thinking, particularly toward "inner-city students," is ethically problematic and inconsistent with creating true democratic education possibilities. This key question is addressed in this paper in four parts: (1) the connection between neoliberalism and public education, (2) the meaning and forms of deficit thinking with respect to teaching, (3) ethical implications of deficit thinking on students' public school experiences, and (4) a call for a genuine democratic education in teacher education.
\end{abstract}

\section{Introduction}

t was on a crisp fall day after school when I decided that I would try out for my elementary school's basketball team. I arrived excited and ready to play my very best, until a sideline remark came from my gym teacher. Making no eye contact, having no intonation in her voice, barely noticing me, she briefly said; "your people won't allow you to be on a school team. Why don't you just go home and learn how to cook some samosas as that will be useful to you in the future-and bring me some tomorrow." I could not believe what I had heard. I felt a surge of strong emotions come through me, yet simultaneously my 
mind was confused and I felt the world stop. I felt my heart tremble, eyes water, and hands lose grip of my favorite blue basketball. I came home and went straight to my room that I shared with my sisters, changed my clothes, and went straight to bed by $4 \mathrm{pm}$. It was the longest evening of deep disappointment I had experienced in the total of ten years of being in the world. At the age of ten, I blamed myself for everything: for who I was and where I had come from. However, the worst part of this sad evening was that I thought and felt that I had no way of changing any of it and it was the "way it is supposed to be."

This is a first-hand account from one of the author's (Sharma) elementary school experiences. In retrospect, as an Indian-Canadian educator who embraces her culture and identity, she recognizes the deeply seated roots of discrimination in her fifth grade health and physical education teacher's sideline remark. The teacher had assumed that because Sharma was Indian, she could not try out for the team. Moreover, this teacher used stereotyped perceptions of Indian culture to rationalize her decision of not allowing the author to try out.

We believe that the underlying problem was not Sharma's ability to play basketball. Rather, it was the health and physical education teacher's deficit thinking about her racially marginalized identity that denied her access to simply try out for the team. The ethical implications of such a vivid childhood memory resonated for many years with the author, and drives this critical analysis and perspective of what grounds such narratives with respect to students' embracing of a racially marginalized identity in a public school setting.

In our neoliberal context, the field of teacher education and education in general face many challenges and tensions (Zeichner, 2009; Cochran-Smith \& Zeichner, 2005; Giroux, 2004; Smyth, 2011; Down \& Smyth, 2012). One such crucial challenge that arises in teacher education deals with the tensions of deficit thinking (Kincheloe, 2009; Writer \& Oesterreich, 2012; Waddell, 2013; Aragon, Culpepper, McKee, \& Perkins, 2014; Riojas-Cortez \& Flores, 2009; Katsarou, Picower, \& Stovall, 2010). Specifically: why is deficit thinking, particularly toward "inner city students"," ethically problematic and inconsistent with creating true democratic teacher education possibilities? This is the major question tackled in this paper, which is divided into four parts: (1) the connection between neoliberalism and public education, (2) the meaning and forms of deficit thinking with respect to teaching, (3) ethical implications of deficit thinking on students' public school experiences, and (4) a call for a genuine democratic education in teacher education. 


\section{The Connection Between Neoliberalism and Public Education}

Neoliberalism has come to be understood from various perspectives, each embedded in different ethical frameworks. For this paper, we use Michael Apple's (2011) conception of neoliberalism as a marketplace ideology that has entered the public school system from a critical framework (Giroux, 1992). Neoliberal policies may be well intentioned, but their "outcomes" are negatively experienced and embodied by racially marginalized students (Darder, 2012).

From the neoliberal standpoint it is in the best interest of the economy to open up educational services that market to "profit educational management skills" (Ross \& Gibson, 2006). Neoliberal policies support upper- and middle-class students as they are seen to bring the most "profit" to the economy and cut down on the resources and finances allotted to public education for working-class students (Ross \& Gibson, 2006):

Efforts are made to reduce educational costs, often through economies of scale. Closing school libraries, reducing the number of special needs teachers, increasing class size, expanding online learning programs are examples. These actions intensify the work of teachers and isolate them from decision making and from one another. (p. 4)

Neoliberal practices such as cutting back on funding for public schools are part of the reason why the status quo (which ensures social class distinctions between upper-, middle-, and lower-class communities) is perpetuated. Consequently, public education, despite being advertised as "free" or "equal" education for all, in reality becomes inaccessible to many students including those who have been traditionally marginalized due to their race, culture, and socio-economic status (Ladson-Billings, 1994; Delpit, 1995).

Moreover, the quality of education that working-class students receive is inferior, because the demands put on inexperienced new teachers who make up the majority of teachers in inner-city schools (e.g., delivering standardized tests, working with large class sizes, and dealing with fewer resources) are often too overwhelming and leave no space for teachers to develop a more equitable teaching environment (Portelli, Shields, \& Vibert, 2007). Thus, students from working-class families end up with lower expectations from teachers. As result, they experience fewer possibilities for their future (lower graduation rates, limited job market opportunities, low-collar jobs, and limited 
mobility from their social class) (Ladson-Billings, 1994). As Ayers and Ford (1996) put it: "Savage inequalities in the public education available to students of different racial and class backgrounds reflect growing social and economic polarization -- and squander the potential of our youth" (p. 145).

Reid's (2005) work further supports our argument as it explains how the neoliberalism agenda to globalize and marketize education allows private corporations to capitalize on education, while decreasing the quality of education for the low socio-economic background students. Lipman (as quoted by Ross \& Gibson, 2006) and Meier (2002) believe that the standardized tests, which have also been introduced by a neoliberal agenda, help increase the gap between the social classes and maintain the status quo. Anyon (1980) also claims that the job market displays the socio-economic and political disadvantage that has been placed on students who come from low socio-economic backgrounds.

Keeping these key arguments in mind, in the next section we provide an understanding and analysis of the concept of "deficit thinking" as it arises from the literature, with a focus on marginalized and racialized public school students.

\section{The Meaning and Forms of Deficit Mentality With Respect to Teaching}

\section{Defining Deficit Thinking}

We know deficit thinking is seen and felt in many narratives, such as the one we began with, that lives in the souls of racially marginalized students. Katsarou and colleagues (2010) claim that teachers who hold deficit views of racially marginalized students often:

[s]ee their students only as a laundry-list of problems, these educators are unable to look past students' more challenging behavior, [thus] making meaningful and reciprocal relationships impossible. Unable to connect to their students, their efforts at classroom management and instruction fail, and they in turn blame their students for what has ultimately stemmed from their negative and stereotyped views for their students. (p. 139)

This deficit disposition is a complicated, but often unconsciously supported nature of well-intentioned teachers falling into a trap of stereotypes about students with whom 
they are unable to identify (Katsarou et al., 2010). Deficit assumptions and dispositions seem to be deeply embedded in school culture and pedagogy that are sometimes invisible but powerfully felt (Valencia, 2010). There are different ways of describing the negative effects and unethical implications that deficit thinking has, particularly on racially marginalized students. Many have argued that the neoliberal context and policies have made it easier for a deficit mentality to continue to be reproduced (Valencia, 2010; Portelli, 2010). For the sake of clarity, we will use the following characterization of deficit thinking:

Deficit thinking is a very common way of thinking which affects our general way of being in and constructing the world. Differences from the 'norm' are immediately seen as being deprived, negative, and disadvantaged. It never questions the legitimacy of what is deemed to be normal nor does it consider that differences may actually go beyond expected norms. It discourages teachers and administrators from recognizing the positive values of certain abilities, dispositions, and actions.

Deficit thinking leads to stereotyping and prejudging. It marginalizes certain people on the basis of misinformation and misconstructions. (Based on Portelli, 2010, 2013)

With this characterization in mind, we analyzed and categorized the literature on deficit mentality into three different frameworks that create, sustain, and often "justify" this thinking. They are namely: pseudo-scientific, sociological/cultural, and socio-economic. While these frameworks are conceptually distinct, in practice they overlap.

\section{The Three Frameworks of Deficit Thinking}

Deficit thinking created by a pseudo-scientific framework. The pseudoscientific framework for deficit thinking emerges from using scientific methodology and authority in unethical ways that often (re)produce unreliable "factual" evidence (Hyslop-Margison \& Naseem, 2008). "Convergent thinking"3 lies at the heart of pseudoscientism; convergent thinking often allows researchers to remain consistent with prevailing theories (e.g., Bell Curve theory and No Child Left Behind legislation [NCLB]). These "scientific" theories (i.e., IQ tests now known as standardized tests) used in schools to assess each student's intelligence are based on unquestioned assumptions about political agendas (Hyslop-Margison \& Naseem, 2008). Often these theories claim the results from scientifically conducted tests and surveys are summarized and used to provide statistical "facts" that are true about racially marginalized communities (Hyslop-Margison \& Naseem, 2008). Teachers then use these test scores and summaries as an indicator of the potential capabilities of an individual student or a sub-cultural 
grouping in their class. Overwhelmingly, the lowest test scores have been found in racially marginalized community children, and thus a re-stereotyping of their "low" capacity for success or them being "high risk students" is flagged (Writer \& Oesterreich, 2012; Aragon, Culpepper, McKee, \& Perkins, 2013). However, despite the scientific methodology used in these surveys/tests to analyze and compile the facts, the research itself is pseudo in nature (Hyslop-Margison \& Naseem, 2008).

Critics of pseudo-science researchers argue that these "facts" are not reflective of the racially marginalized communities because they are created, processed, and analyzed with a political agenda that sustains neoliberal values (Hyslop-Margison \& Naseem, 2008). Thus, the questions that need to be asked about this "scientific research" are: what criteria are used to create these surveys/tests? Who is responsible for creating and delivering these surveys/tests? Who does this research benefit? How are these "facts" used to reinforce deficit assumptions about racially marginalized communities? Moreover, the contexts in which these surveys/tests are given are often not taken into consideration (Hyslop-Margison \& Naseem, 2008; Shields, Bishop, \& Mazawi, 2005).

Deficit thinking created by a sociological-cultural framework. The sociologicalcultural framework is one that creates, sustains, and often "justifies" deficit thinking; sometimes it uses the results of the pseudo-scientific standardized tests to build stereotypical views of racially marginalized students. Aragon and colleagues (2013) articulate the former claim clearly when they state,

...because teachers do not want to see Brown and Black children as being impacted by both institutional forces and individual choices, they commit the fallacy of interpreting the collective low achievement of Brown and Black children as being due to their individual lack of tenacity, hard work, or merit, which ends up being a racist belief. (p. 548)

Valenzuela (1999), Garza and Crawford (2005), Yosso (2005), and Cooper (2006) also argue that deficit thinking has its roots in sociological/cultural differences. Moreover, they contend that the treatment shown by some educators towards inner-city students is presumptuous and often disrespectful. This presumptuous treatment is most visible in the interactions between teacher and students (Valenzuela, 1999). Differing curricular, pedagogical, and student evaluation practices emphasize different cognitive and behavioural skills in each social setting. Such practices contribute to the development of social identity in "behavioural," "high risk," "immigrant," and "special needs" students with respect to physical and symbolic capital, authority, and the process of work, which in turn make up their social class identity (Anyon, 1980; Brown, 2010). 
Interestingly, Garza and Crawford (2005) critique the diversity of students as a welcome addition to an inclusive school, which at the same time legitimizes the differences between the dominant and the "diverse" students. Garza and Crawford (2005) state that a hegemonic multiculturalism has been created as "the result of dissonance between a school's desire to promote an inclusive and welcoming learning environment for their culturally and linguistically diverse students and [maintain a] persuasive, assimilation agenda that underlies instructional practices and programs designed to educate them" (p. 601). Thus, this "all-inclusive" approach "ultimately privileges the dominant group's conceptualization of what diversity is and how diverse identities should be positioned and expressed..." (p. 602). The impact of such a hierarchy is then demonstrated in the teacher's deficit-based pedagogical approach towards racially marginalized students.

Deficit thinking: A socio-economical framework. The socio-economic framework demonstrates the connection between social class, economic status, and deficit thinking. Anyon (1980) defines "social class" as an outcome of three relationships: (i) the way a person relates to the process of producing goods, services, and culture in society; (ii) how one relates to the aspects of the production process through one's own work; and, (iii) the relations one has to the system of ownership towards other people and themselves at work in society. However, the question left unanswered is: How are students' social class identities formed and judged during their schooling process (Meier, 2002)? In order to answer this question, it is important for us to examine how students are taught and under what conditions.

The teaching approach that is used when teaching working-class students is explicitly instructional and often involves rote behaviour (Meier, 2002, Nieto \& Bode, 2012). Instructional and rote teaching is rooted in the deficit assumption that workingclass students are incapable of learning any applied knowledge skills or critical thinking skills (Meier, 2002). Moreover, many teachers in working-class schools "attempt to control classroom time and space by making decisions without consulting the students and without explaining the basis for their decisions" (Anyon, 1980, p. 76). As a result of this approach, knowledge skills that are required for powerful social positions (e.g., lawyers, doctors, managers) are withheld from the working class (Apple, 2011). Thus, working-class students are not given the opportunity to excel at attaining positions of social power (Apple, 2011).

Hoschschild and Scovronick (2004) also support Apple's conclusion. They claim,

[i]nequalities in family wealth are a major cause of inequalities in schooling [e.g. the physical conditions of the school, the unqualified teachers, the bias standardized 
tests, the streaming of classes], and inequalities in schooling do much to reinforce inequalities of wealth among family in the next generation. (Hoschschild and Scovronick as cited in Books, 2004, p. 106)

In other words, Hoschschild and Scovronick state that the deficit teaching approach in schools helps reinforce socio-economic inequities towards the working class. Due to having a low socio-economic class association, Gaab (2004) explains that working-class students were treated with a deficit approach because they were incapable of "success" due to their low economic status. In response to these deficit-based social policies and ideologies aimed at working-class students, neoliberalism advises to "fix" the students by creating programs (e.g., behavioural classes, special education classes, home school programs) (Gaab, 2004).

Proponents [in positions of power] believed that by turning these [poor] students into useful, productive citizens [through social programs] they could eliminate the social ills of society. Unfortunately, these social programs were initiated with much indifference for the lives of the poor... (Gaab, 1993, p. 179)

Due to the low level of "success" that resulted from these social programs, "a pervasive belief that the poor were beyond redemption" (p. 179) was established. Such a belief has reinforced and justified deficit thinking attitudes and practices toward workingclass students (Gaab, 1993). Pervasive and dominant deficit attitudes in respect to poor students have helped to justify the unequal distribution of money toward the education of the poor (Apple, 2011). Thus, teachers who work in inner-city schools have a high turnover rate and rightfully complain about the resources and conditions of the school (Aragon et al., 2013).

\section{The Six Components of Deficit Thinking}

According to Valencia (2012) there are six aspects that describe the act of deficit thinking. For the first component Valencia uses Ryan's (1971) phrase "blaming the victim" to explain the beginning oppressive cycle of deficit thinking. Ryan (1971) explains how people in positions of power often recognize social problems, then do a comparative study that emphasizes differences between the disadvantaged and the advantaged, and, as a result, connect the differences to the cause of social problems (Valencia, 2012). Furthermore, people in positions of power get the government to intervene and "correct" the differences (Valencia, 2012). Unfortunately, this process occurs so smoothly that it seems rational and goes unquestioned and the victims suffer (Valencia, 2012). 
This relationship between the victims and the victim-blamers then becomes a cycle of oppression, which is the second component of deficit thinking (Valencia, 2012).

The second component of deficit thinking is a cycle of oppression which ensures that victims and the victim-blamer groups remain separate, thus allowing for deficit thinking to be seen as a rational conclusion (Valencia, 2012). The effects of the oppressive cycle help to perpetuate the pseudoscientific nature of deficit thinking, which is the third component of Valencia's conception.

Valencia (2012) claims that the pseudoscientific nature of deficit thinking is built upon assumptions of accuracy (e.g., high stake testing) and generalizations that do not logically follow from one to another (e.g., victim-blamer group accusing oppressed as the cause of social problems). This pseudo-scientific condition is based on the values of the dominant class, which then acts as the norm against which all marginalized people are compared, and therefore required to aspire (Valencia, 2012). It is because deficit thinking goes through similar motions such as the "scientific method" that it gains acceptance (as the "scientific method" is regarded as an authoritative and privileged discourse) (Valencia, 2012). This scientific method is then seen to be sufficient to ground a diagnosis of marginalized and racialized students. However, during different temporal periods, which is the fourth component of deficit thinking, the nature of the scientific argument for deficit thinking changes (Valencia, 2012). Deficit thinking is influenced by the time period in which it occurs and as a result moulds itself correspondingly (Valencia, 2012).

Valencia (2012) claims the diagnosis process to be the fifth component of the deficit thinking. The diagnosis that follows can be understood as the result of a cycle that begins with educators describing the deficits, deficiencies, limitations, and shortcomings in students from low socio-economic backgrounds; then, educators explain these deficits by placing their origins in terms of genetic characteristics; finally these explanations are used to predict the perpetuation and accumulation of these very deficits. As a result, educators prescribe educational interventions designed to remedy the deficits (Valencia, 2012).

The sixth component of Valencia's (2012) form of deficit thinking is informed by heterodoxical views. Heterodoxical views are those that challenge the dominant class's (i.e., upper-middle European class) norms or "orthodoxical" ideas on what standards should be upheld by society (Valencia, 2012). Valencia's work in itself exposes a heterodoxical view of deficit thinking that encourages the public to re-evaluate and re-analyze the conditions of deficit thinking. 


\section{Ethical Implication of Deficit Thinking on Students' Public Schooling Experiences}

\section{The Effects and Implications of the Pseudo-Scientific Framework}

Unquestioned assumptions rooted in pseudo-scientific methodology frequently lead to errors in the dominant discourse about teaching racially marginalized communities, and the level of learning that is possible in them (Hyslop-Margison \& Naseem, 2008). These errors often create, reinforce, and sustain deficit thinking assumptions about inner-city students which then become incorporated as given truths into deficit teaching practices (Valencia, 2010). Pseudo-science offers a "causal explanation of why humans act in certain ways" (Hyslop-Margison \& Naseem, 2008, p. 40). Such an explanation, "inevitably involves normative and contextual components that cannot be ignored when accurately explaining individual or group behaviours. Under these conditions, claims of objectivity, reliability, and validity in human science are highly problematic" (p. 40). In other words, "scientific" causal explanations are problematic because they create norms that are developed from a study done on a particular group of people, that are then generalized to encompass everyone from that community (Hyslop-Margison \& Naseem, 2008). Without being culturally sensitive, these norms set the standards to which everyone is compared and contrasted (HyslopMargison \& Naseem, 2008). We wonder why these implications are not taken up in teacher education programs, in particular the nature of standardized testing and how it is utilized to further create a gap between racially marginalized students and White middle-class students.

Unfortunately, the effects of these pseudo-scientific theories are deeply felt and can often remain with marginalized children for the duration of their life. Valencia (2010) states that the effects of using a pseudo-scientific methodology to diagnose deficit thinking, which aims to "describe, explain, predict and prescribe" its victim's behaviour, has caused a stigma against "racially marginalized students": "...[T]he effect of these interventions were primarily felt by several racially marginalized students as they were misjudged, labeled and underwent all kinds of discrimination...the long-term effects of this discrimination have shaped and influenced educational thought and practice" (Valencia, 1997, p. 7).

Thus, discriminatory attitudes, actions and dispositions are held against "racially marginalized students" (Valencia, 2010). Shields and colleagues (2005) agree that the "scientific" labeling process makes students who have been labeled or who fit the label, believe it as a statement of truth. They argue that a structural/positivist form of 
science is seen as an authoritative voice to truth and consequently, the pathologizing process that happens to racially marginalized students is accepted as a norm and goes unchallenged (Shields et al., 2005). We urge teacher educators and teachers in the field to ethically respond to these negative (often internalized) deficit labels placed upon racially marginalized students, by critically reflecting upon the impact of such labels and stereotypes on their students. We agree with Katsarou and colleagues (2010) who state that deficit thinking can only be interrupted when teachers acknowledge that, by looking simply at the statistics of test results, the whole child is not being seen. Moreover, Katsarou et al. (2010) conclude, "[w]hen the teacher educator asks the [teacher] candidates to move from seeing only deficits to recognizing the whole child and their strengths, [teacher] candidates are in a better position to be able to develop solidarity with their students' communities" (p. 145). We also stand by this position in honour of educating the whole child, not merely what test scores state is the capability of the child.

\section{The Effects and Implications of the Sociological-Cultural Framework}

Valenzuela (1999) states that the major effect of deficit thinking, which targets the sociological-cultural backgrounds of racially marginalized students, is a sense of alienation. He claims that instead of seeing these students as capable of using agency, critical thinking, and being resistant to the school's lack of connectedness to them, many school officials label them as disengaged individuals who act out against school rules (Valenzuela, 1999). In other words, these racially marginalized students are labeled as disrespectful, disengaged, unappreciative, and rebellious because they do not adhere to the dominant neoliberal norms that construct school culture (Valenzuela, 1999). Garza and Crawford (2005) also suggest that a binary contrast is drawn between dominant norms and racially marginalized lived experiences, which are seen as abnormal due to deficit thinking. "The cultural capital of the dominant group and their related manners of interacting and producing knowledge are the basis from which 'normality' is constructed within the broader society and upon which value is assigned" (Garza \& Crawford, 2005, p. 602), thus making anyone outside the dominant out group to be abnormal. In response to such implications,

[o]ur role as teacher educators is to increase our students' [i.e., teacher candidates] experiences beyond what they believe about the [marginalized] families they will serve. Engaging teacher candidates in working with families will certainly extend their understanding and will provide them with the tools to become effective teachers. (Riojas-Cotez \& Flores, 2009, p. 238) 


\section{The Effects and Implications of the Socio-Economic Framework}

Gaab (1993) claims that because, “...deficit thinking continues to exist in our schools, [it is] communicating to [racially marginalized] students that they are somehow less deserving" (p. 183) of school funding and well-equipped schools. Moreover, Gaab quotes Anyon to emphasize that socio-economic research reveals that, "... many working class and poor schools are teaching students in rote, repetitive ways that exclude discussion and higher level thinking in order to provide students the skills believed to be needed in the blue-collar workforce" (Anyon as cited in Gaab, 1993, p. 183). Deficit thinking assumptions toward the capabilities of working-class students become reinforced (Nieto \& Bode, 2012). Moreover, Cuban's (2004) research also seems to blame the low socio-economic background of students for being the cause of a declining neoliberal economy, and thus "justify" deficit assumptions about these students.

These detrimental effects of the three conceptual frameworks for deficit thinking have the following negative effects and implications on racially marginalized students: internalization of a negative self-identity, alienation, discrimination, student disengagement, and a lack of trust and belief in the school system. Thus, neoliberal practices such as standardized tests for "measurability," rote learning for "efficiency," and streaming/labeling for "success at the individual level" are smoke screens for sustaining and promoting deficit attitudes towards racially marginalized students (Groenke \& Hatch, 2009). As teacher educators we need to encourage our "[p]reservice teachers [to] shift passive ideas of race, socioeconomics, gender, and so forth, to an assertive sociocultural and anti-oppressive consciousness" (Cross, 2003; Ladson-Billings, 2006 as quoted in Aragon et al., 2013, p. 566 ).

\section{A Call for a Genuine Democratic Education in Teacher Education}

The heart of the problem of deficit thinking is the neoliberal political agenda in education that reinforces these lop-sided beliefs in the everyday teaching practices and dispositions that our teachers often (un)knowingly embrace is "swept under the rug," and constructed as if it were normal and ethically unproblematic. The problem lies beyond people in positions of authority evading the contentions of inequities in schools as a result of these same agendas that are often not publicly known on a deeper critical level (and are not supposed to be publicly known) (Apple, 2011). The neoliberal agenda displaces what it should be accountable for onto racially marginalized students 
through deficit-based teaching practices, while maintaining its goal of keeping the status quo alive (Apple, 2011).

It is astonishing how many layers of evasive explanations (which sometimes need to be sought out) are offered about why systemic inequities are present in public schools systems (Argon et al., 2013). These explanations are offered without any accountability for why they exist and continue to mask "deficit practices" in the classroom (Skrla \& Scheurich, 2004). Valencia supports the idea that the "accountability" piece is missing in all explanations that have been provided by political authorities: "...[inner city] schools are [often] organized to prevent learning, sustain inequalities in the political economy of education, and [yet] the oppressive macro-politics and practices in education are all held exculpatory in understanding school failure" (Valencia as cited in Portelli et al., 2007, p. 9).

The lack of proper moral accountability toward neoliberal practices and beliefs greatly contributes to the resilience of deficit attitudes and actions.

Many [teacher] candidates complain that they want to teach from a social justice perspective, but there is no way for them to accomplish this. Teacher educators must help them to reveal the cracks in the brick walls created by neoliberal policies so that teachers can implement the kind of pedagogy that is in service to the communities in which they teach. (Katsarou et al., 2010, p. 147)

As teacher educators we must dispel and make apparent the loopholes in deficit-based thinking that are intricately entwined with a neoliberal coating. Such a neoliberal coating has become invisible and now, more than ever, is becoming part of the fabric of teachers' dispositions and teaching pedagogies, which often end up re-oppressing our most vulnerable students.

Garvey (1996), who takes an activist position, reminds us:

[c] ]hance has never yet satisfied hope of a suffering people. Action, self-reliance, the vision of self and the future have been the only means by which the oppressed have seen and realized the light of their own freedom. Up, up, you mighty race! You can accomplish what you will. (p. 210)

At the heart of a truly democratic way of life, is the notion of self-agency. A democratic education needs to provide the explanations for the illusions and misperceptions that neoliberal beliefs have created. Democratic teacher education must extend beyond the 
neoliberal conception of schooling and encourage students and educators to critically examine the deeply rooted ethical problems that underpin deficit thinking. Given the immorality of deficit thinking, as well as the unethical and unjust consequences, we have a moral obligation to support possibilities for a genuinely democratic education in teacher education.

\section{Conclusion}

Teacher education cannot reach its full goal without immersing teacher candidates into the practice of critical reflection of one's own beliefs, attitudes, dispositions, practices, and biases. Questioning mainstream deficit thinking needs to be an integral part of such reflection (Down \& Smyth, 2012). When we critically uncover our own assumptions, often rooted in deficit thinking, then we can collectively work on how to diminish and eliminate such deficit thinking practices (Ladson-Billings, 2006). We recognize that not all teachers or administrators are willing to "give up their privileges" by acknowledging their biases. And that going against the grain (i.e., being morally responsible for them) requires a constant struggle that is often demanding and difficult. However, we believe it is crucial that they are made aware and understand the serious effects and implications of deficit thinking, and are able to begin thinking about how they can be morally responsible and contribute to democratic schooling possibilities. ${ }^{4}$

\section{Notes}

1. This paper is based on ideas originally developed in Sharma, 2009. In some instances sentences from this document have been incorporated into this paper.

2. For the purposes of this paper, "inner-city students" refer to racially marginalized students that come from low socio-economic backgrounds and attend public schools.

3. Convergent thinking is the opposite of divergent thinking and thus assists in reinforcing deficit thinking assumptions based on pseudo-scientific rationalization, as described by Hyslop-Margison and Naseem, 2008.

4. We believe these critical dialogues must include active listening, mutual respect, true openness to dialogue, and genuine compassion for the "other." 


\section{References}

Anyon, J. (1980). Social class and the hidden curriculum of work. Journal of Education, 1, 67-92.

Apple, M. W. (2011). Democratic education in neoliberal and neoconservative times. International Studies in Sociology of Education, 21(1), 21-31.

Aragon, A., Culpepper, S. A., McKee, M. W., \& Perkins, M. (2014). Understanding profiles of preservice teachers with different levels of commitment to teaching in urban schools. Urban Education, 49(5), 543-573.

Ayers, W., \& Ford, P. (Eds.). (1996). City kids, city teachers: Reports from the front Row. New York: The New York Press.

Books, S. (2004). Poverty and schooling in the U.S.: Contexts and consequences. New Jersey: Lawrence Erlbaum Associates.

Brown, K. D. (2010). Is this what we want them to say? Examining the tensions in what U.S. preservice teachers say about risk and academic achievement. Teaching and Teacher Education, 26, 1077-1087.

Cochran-Smith, M., \& Zeichner, K. (Eds.). (2005). Studying teacher education. New York: Routledge.

Cooper, B. (2006). Deficit Thinking, Learn University of North Carolina. North Carolina: University of North Carolina Publishers.

Cuban, L. (2004). Making public schools businesslike ... again. Political Science and Politics, 237-240. doi:10.1017.S1049096504004159.

Darder, A. (2012). Neoliberalism in the academic borderlands: An on-going struggle for equality and human rights. Educational Studies, 48: 412-426.

Delpit, L. (1995). Other people's children: Cultural conflict in the classroom. New York: The New Press.

Down, B., \& Smyth, J. (Eds.) (2012). Critical voices in teacher education: Teaching for social justice in conservative times. New York: Springer.

Gaab, M. (1993). Book Review on: "Lives on the edge: Single mothers and their students in the other America." Chicago: University of Chicago.

Gaab, M. (2004). Book Review on: "Lives on the edge: Single mothers and their students in the other America." Educational Studies: A Journal of the American Educational Studies Association, 36(2).

Garvey, M. (1996). City kids city teachers. New York: The New Press.

Garza, A., \& Crawford, L. (2005). Hegemonic multiculturalism: English immersion, ideology, and subtractive schooling. Bilingual Research Journal: The Journal of the National Association for Bilingual Education, 29(3), 599-619.

Giroux, H. (1992). Resisting difference: Cultural studies and the discourse of critical pedagogy. In Lawrence Grossberg, Cary Nelson, and Paula A. Treichler (Eds.) Cultural Studies. New York: Routledge.

Giroux, H. (2004). The terror of neoliberalism: Authoritarian and the eclipse of democracy. Boulder, CO: Paradigm.

Groenke, S. L., \& Hatch, J.A. (Eds.). (2009). Critical pedagogy and teacher education in the neoliberal era. New York: Springer.

Hyslop-Margison, E., \& Naseem, A. (2008). Scientism and education: Empirical research as neo-liberal ideology. Dordrecht, NLD: Springer Netherlands.

Katsarou, E., Picower, B., \& Stovall, D. (2010). Acts of solidarity: Developing urban social justice educators in the struggle for quality public education. Teacher Education Quarterly, 37(3), 137-151.

Kincheloe, J. (2009). "Contextualizing the madness: A critical analysis of the assault on teacher education and schools," in Susan L. Groenke \& J. Amos Hatch, Critical Pedagogy and Teacher Education in the Neoliberal Era, Springer: 19-36.

Ladson-Billings, G. (1994). The dreamkeepers, successful teachers of African American children. San Francisco: Jossey-Bass. 
Ladson-Billings, G. (2006). "Yes, but how do we do it?": Practicing culturally relevant pedagogy. In J. Landsman \& C. Lewis (Eds.), White teachers/diverse classrooms: A guide to building inclusive schools, promoting high expectations, and eliminating racism (pp. 29-42). Sterling, VA: Stylus.

Meier, D. (2002). In schools we trust: Creating community of learning in an era of testing and standardization. Boston: Beacon Press.

Nieto, S., \& Bode, P. (2012). Affirming diversity: The sociopolitical context of multicultural education (6th ed.). Boston: Pearson.

Portelli, J., Shields, C., \& Vibert, A. (2007). Toward an equitable education: Poverty, diversity, and students at risk. Canada: National Library and Archives Canada Cataloguing in Publication.

Portelli, J.P. (2010). Leadership for equity in education: Deficit mentality is a major challenge in Fedcan Blog. Retrieved from: http://www. ideas-idees.ca/blog/leadership-equity-edu cation-deficit-mentality-major-challenge

Portelli, J.P. (2013). Deficit mentality and the need for subversion: Reflections on Milani, in Carmel Borg, Mario Cardona, and Sandro Caruana (Eds.), Don Lorenzo Milani and Education. Palgrave, 213-218.

Reid, A. (2005). "Rethinking the democratic purposes of public schooling in a globalizing world" in Michael Apple et al. (Eds.), Globalizing education: Policies, pedagogies, and politics. New York: Peter Lang.

Riojas-Cortez, M., \& Flores, B. B., (2009). Sin olividar a los padres: Families collaborating within school and university partnerships. Journal of Latinos and Education, 8(3), 231-239.

Ross, W., \& Gibson, R. (Eds.). (2006). Neoliberalism and educational reform. $\mathrm{NJ}$ : Hampton Press.

Sharma, M. (2009). Inner city students: Stamped, labeled and shipped out - Deficit thinking and democracy in an age of neoliberalism (Masters Thesis). University of Toronto.
Shields, C., Bishop, R., \& Mazawi, A. (2005). Pathologizing practices: The impact of deficit thinking on education. New York: Peter Lang Publishing Inc.

Skrla, L., \& Scheurich, J. J. (Eds.). (2004). Educational equity and accountability: Paradigms, policies, and politics. New York: Routledge Falmer.

Smyth, J. (2011). Critical pedagogy for social justice. New York: Continuum.

Valencia, R. R. (Ed.). (1997). The evolution of deficit thinking: Educational thought and practice. London: The Falmer Press.

Valencia, R. R. (2010). Dismantling contemporary deficit thinking: Educational thought and practice. New York: Routledge.

Valencia, R. R. (Ed.). (2012). The evolution of deficit thinking: Educational thought and practice. Routledge.

Valenzuela, A. (1999). Subtractive schooling: U.S.- Mexican youth and the politics of caring. Albany: State University of New York Press.

Waddell, J. H. (2013). Working with families in urban teacher education: A critical need for all students. The Teacher Educator, 48(4), 276-295.

Writer, J. H., \& Oesterreich, H. A. (2012). Native women teacher candidates "with strength": Rejecting deficits and restructuring institutions. Action in Teacher Education, 33(5-6), 509-523.

Yosso, T. J. (2005). Whose culture has capital? A critical race theory discussion of community cultural wealth. Race Ethnicity and Education, 8(1), 61-91.

Zeichner, K. (2009). Teacher education and the struggle for social justice. New York: Routledge. 


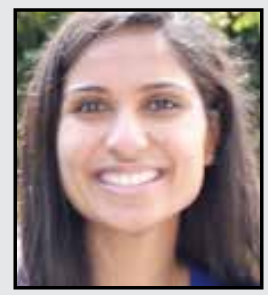

Manu Sharma is a faculty member and the Experiential Learning Specialist at the University of Windsor. She teaches in the B.Ed program and the Masters program. In addition, she has taught with the University of Toronto, the Toronto District School Board and internationally in Antigua and Barbuda, Germany, Japan, and Tanzania. Her research interests are in teacher education program initiatives, equity and diversity studies in education, critical pedagogy and andragogy, international and community-based learning and experiential learning.

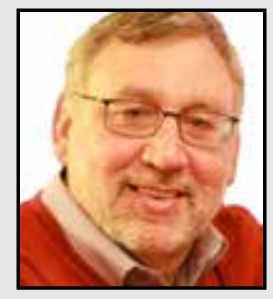

John P. Portelli, a former schoolteacher, is a Professor in the Department of Social Justice Education with a crossappointment in the Department of Leadership, Higher and Adult Education at OISE, University of Toronto, where he also co-directs the Centre for Leadership and Diversity. His research interests include philosophy of education, democratic theory and pedagogy, equity issues in leadership and policy, and student engagement and students at risk. He has authored, co-authored, and co-edited 10 books including two collections of poetry. 